\title{
Knowledge Production in Networked Practice-based Innovation Processes - Interrogative Model as a Methodological Approach
}

\author{
Vesa Harmaakorpi and Arto Mutanen \\ Lappeenranta University of Technology, Lahti Unit, Finland
}

vesa.harmaakorpi@lut.fi; arto.mutanen@lut.fi

\begin{abstract}
Innovations emerge increasingly in practice-based processes combining both practical and scientific knowledge. The innovation processes are typically cooperative non-linear processes where knowledge production is triggered by different kinds of sources. Innovation based on a scientific theoretical approach is an exception rather than the rule as such a source. Therefore, knowledge production in practice-based, networked innovation processes requires new methodological approaches. The interrogative model of inquiry, having its origins in the field of theoret ical philosophy, is presented as such a methodological approach. A mental exercise of knowledge production in the middle ground between the practice-based metal industry and science-based nanotechnology is used to clarify the methodological approach.
\end{abstract}

Keywords: innovation, knowledge production, innovation systems, interrogative model, philosophy

\section{Introduction}

Innovation is said to be the driving force in today's world. Earlier, innovation policies have been very much equivalent to the science and technology policies emphasising the science push effect in creating innovations. However, the causality between science and innovation has proved to be weaker than expected (Innovation in Europe, 2004; Schienst ock \& Hämäläinen, 2001) creat ing a demand to foster other sources of innovation. The effectiveness of the reigning waterfall model (basic research - applied research - development) can be strongly questioned. For example, Finland is among thethree best countries in the world in research inputs leading to only about $15^{\text {th }}$ place in living standards. The national innovation system does not produce the results expected from the research inputs.

Schienstock and Hämäläinen (2001) suggest that a system approach-based, network-facilitating, innovation policy is the modern way to enhance the innovation environment (see also Harmaakorpi, 2006; Harmaakorpi \& T ura, 2006). The network-facilitating innovation policy pays particular attention to the dialogue between the co-operat ors. The dialogue is aiming to tackle the

Material published as part of this publication, either on-line or in print, is copyrighted by the Informing Science Institute. Permission to make digital or paper copy of part or all of these works for personal or classroomuse is granted without fee provided that the copies are not made or distributed for profit or commercial advantage AND that copies 1) bear this notice in full and 2) give the full citation on the first page. It is permissible to abstract these works so long as credit is given. To copy in all other cases or to republish or to post on a serveror to redistribute to lists requires specific permission and payment of fee. Contact Publisher@InformingScience.org to request redistribution permission. whole problem in the innovation system. The system approach is not only a tool for studying innovation processes, but also a conceptual framework for innovation policies and strat egies (Edquist, 1997). The system approach recognises that different parts of the innovation process may become bottlenecks in the successful development of new products and processes leading to many kinds of systemic failures (Lundvall \& Borrás, 
1999; Schienstock \& Hämäläinen, 2001). All such failures are potential targets of regional innovation policies and strategies (Technology, productivity, and job creation, 1998).

This present study focuses on one obvious bottleneck in the innovation systems: the wrong kind of methodology in producing knowledge in the networked multi-actor innovation processes. These processes occur within a practical context. In this kind of practice-based processes there is a strong need to combine knowledge interests from theory and practice, as well as knowledge from different disciplines. The traditional model of developing novel knowledge based on existing theories gives a totally insufficient methodological approach in this present environment. Also a new kind of characterization for expertise is needed. The experts in the innovation processes cannot just be pouring knowledge into the innovat ing partners and then disappear from the scene; they have to be interactive partners in the collective learning processes leading to successful innovations.

The new kind of practice-based networked innovation processes demand a new kind of practicebased research methodology. This present article introduces the interrogative model of inquiry as such a methodology. The model was originally developed in the field of theoretical philosophy. This article is the first attempt to outline the opportunities given by the methodology in the networked innovation environment.

\section{Networked Innovation Environment}

Innovation was earlier seen as a radical invention accomplished by a heroic inventor in linear innovation processes (Schumpeter, 1942). In the traditional linear model of innovation (science push and market pull models) the basic idea is to characterize innovations as (causal) linear chains. In the science push model the chain runs as follows: First, theoretical knowledge is generated in basic science. After this, the generated knowledge flows do wn to a practical context in which the knowledge is applied in problem solving. Eventually, after these steps an innovation may occur. The chain runs only in one direction: all the questions and information come into the process from an earlier or the present state of the chain. In the market pull model the chain is the same but the questions come from the market. Both models characterize innovation as something far from practical, everyday life. Moreover, neither model can explain success and lack of success in innovation processes. That is, innovation seems to be an irrational process.

Nowadays innovation is considered most often to be a result of cooperation in normal social and economic activities (Kline \& Rosenberg, 1986; Lundvall, 1988). The innovation process normally includes many kinds of interaction, and innovations do not haveto be radical; on the contrary, they are incremental social and organizational changes, as well as technological advancements. Consequently, innovations are not just the results of scientific work in a laborat ory-like environment. They are done in networks where actors with different backgrounds are involved in the process setting new demand for innovativeness. The science push effect as the driving force of innovations is an exception rather than a rule in these processes (Schienstock \& Hämäläinen, 2001). A more influential source of innovations seems to be factors like the ability to interact, learn collectively, and build trust ful relations between the innovating partners (Harmaakorpi, 2006). Innovativeness depends in most cases on the innovation network's ability to interact rather than on an individual actor's progress in a particular scientific field.

An innovation system consists of innovative networks with different kinds of social relationships. Social structure, especially in the forms of social networks, affect economical outcomes since the networks affect the flow and the quality of the information (Granovetter, 2005). In his influential work Granovetter (1973) defines the concepts of strong ties and weak ties in social networks. The strength of a tie is a combination of the amount of time, the emotional intensity, the intimacy, and the reciprocal services which characterize the tie (Granovetter, 1973). Strong ties are characterized by common norms and high network density. People in the same strong networks tend to share the same knowledge basis preventing the Schumpeterian knowledge-combining innovation 
processes to emerge (see Schumpeter, 1942). This makes these strong ties, at the same, a little bit conservative.

To open new paths of thought there is also a need for the weak ties (Granovetter, 2005). Burt (1992) argues that innovations are most likely to be found in the structural holes between the dense net work structures (see also Burt, 2004; Walker, Kogut, \& Shan, 1997; Zaheer \& Bell, 2005). An act or able to span the structural holes in a social structure is at higher risk of having good ideas: the new ideas emerge from selection and synthesis across the structural holes between groups (Burt, 2004). An innovation system rich in structural holes offers many opportunities for new networked innovation processes.

However, it is not at all clear how these weak links or structural holes can act as a fruitful platform of innovations. In order to be able to utilise the innovation potential in these structural holes, knowledge should often be transferred between research-oriented and practise-oriented partners; as well as partners of totally different horizontal knowledge interests (interdisciplinarity). Autio (1998) defines two subsystems in innovation systems: i) knowledge generation and diffusion subsystem and ii) knowledge application and exploitation sub-system. Dialogue is a presupposition of a common innovation process within different sub-systems. Even in the sametechnological field the mode of language differs in basic research and practical production. This makes it difficult even to picture the innovation potential in the structural hole. The situation is the same between different technological disciplines. There may be a desire to span the structural hole between a partner with research-oriented knowledge interest in one technological field and a partner with practice-oriented knowledge interest in another technological field, for example, the relationship between basic nanotechnology research and practical innovation processes in the metal industry.

A significant part of the difficulties between the potential innovating partners stems from the information asymmetry on the different sides of a structural hole. The partners on the opposite sides of the structural hole have information of different quality and achieved for their own purposes. The difference is often so great that a new kind of expertise is needed. Following Burt we may identify the expertise as an information broker in the structural hole. A structural hole is an opportunity to broker the flow of information between people and control the form of cooperation that brings together people from the opposite sides of the hole (Burt, 1997). This new kind of expertise usually is located in the intermediate organizations of the innovation system. These organizations include, for example, science and technology parks, business development organizations, and technology transfer organizations of the universities and research centers.

\section{Practice-based Knowledge Production in the Networked Innovation Processes}

The networked innovation environment places new demands for collective knowledge production. Gibbons et al. (1994) define two classes of knowledge use din the innovation processes. Mode 1 is hierarchical and tends to preserve its form. Mode 2 is more heterarchical and transient in nat ure. Mode 1, traditional knowledge production based on single disciplines, is homogeneous and primarily cognit ive knowledge generation context sets within largely academic paradigms. Mode 2, knowledge production, by contrast, is created in broader, heterogeneous interdisciplinary social and economic contexts within an applied setting. One of the key contrasts between the two modes is that in Mode 1 problem-solving is carried out following the codes of practice relevant to a particular discipline and problem-solving whilst under Mode 2 knowledge activity is organized around a particular application and is more diffuse in nature. Gibbons et al. report an epoch change in knowledge activity in innovation networks with a shift from Mode 1 to Mode 2 knowledge creation (Howells, 2000). In this study, the often very practice-oriented Mode 2 knowledge production is seen as the main "business" of the innovation networks. 
In order to understand the new demands for creating knowledge in the - very often practice-based - innovation processes, we must take a little closer look at them. To innovate is an intentional activity in which there is a more or less specified goal to acquire - sometimes only a feeling that something should be done. In an innovation the specification of the goal is the main problem. Also, with product innovations it is very difficult to specify the goal - the commercial end product. In a sense, in an innovation one is trying to develop something new, something that has not occurred before. In this sense, innovation is closely related to discovery in a scientific inquiry (see Kelly, 1996). However, newness in innovation is contextual in a specific sense (Engeström, 1999). Innovations are not made out of nothing. Innovations presuppose systemat ic work including both specific innovative processing of the subject matter and building an innovative environment in order to produce and combine knowledge. Moreover, both factors must be synchronized.

In innovation there is sometimes a need for some new technological or scientific knowledge. To acquire this is just innovation in science - scientific discovery. However, innovation occurs in business contexts and hence the context cannot be specified only by characterizing the framework of research work. Research work that is part and parcel of innovation processes is called practicebased inquiry. The nature of innovation is that the innovation process generates something new. This something new, in a sense, is something unexpected. Of course, the result is surprising also in a scientific knowledge-seeking process. However, the source of the goal is different. In basic research the goal is specified by the underlying theory. The role of the theory can be seen from the fact that the theory or rather the method provides the foundation for justification (Hendricks \& Pedersen, 1997).

In innovation there is no such justifying theory: justification occurs within the markets. Products or services have to be sold out in market. That is the "justification" needed. So, the technological or organizational "justification" is not enough. Hence innovation cannot be reduced to scientific research. Justification given by the market is temporal and has to be constantly earned.

Results in scientific research are underdetermined by the evidence. Hence, there is constantly a need for further justification. In science, experiments play a central role both in the theory formation (abduction) and in the theory testing (induction). Whiletesting, a scientist is trying to formulate a falsifying experiment for the theory. In fact, any experiment can be a falsifying experiment, but no number of positive experiments guarantees the truth of knowledge. Also, a business innovation is a cont inuous process in which new products and services are sought or the existing products and services are further developed. However, in contrast to scient ific innovations there is no such falsifying activity in business innovations - all the activity directs to innovation.

Business innovations are essentially tied to the practical business. That is, the framework of research is only one factorthat determines the context of innovation. To innovate usually means to cooperate. Cooperat ion here means knowledge production within groups of people that have a common interest, determined by the practical context in which the group is working. However, these people often have a very different background (work history, education, etc.)

In practice-based innovation processes there is a common practical context within a problem to be solved which has to be specified. The practical context is a concrete object. Within this practical cont ext each cooperator may have a different point of view, hence the specific problem they have in mind may differ. However, they are solving their problems within the same context. They localize the context in a different way - by asking different questions. Still, they have to have a common dialogue - each of them must be a dialogist in a common dialogue, that is, in a process of building something new within a context. Such common dialogue supposes a common intention. To have this, the dialogists must share some fact ors within a cont ext. These may be, for example, tools (working tools or language) or goals. Usually dialogue supposes that a factor (or a few factors) should be enlarged.

In an innovation process the basic intention is not to acquire consensus. This is exactly the same as in scientific research. In scientific research the basic intention is to acquire truth, not consen- 
sus. In an innovation process the very intention is to create something new - new products, new services, or new habits. These may look like very different from different points of view. However, in a practice-based innovation process, these different points of view have to be synchronized.

It is crucial to elicit questions that synchronize these different points of views. More generally, a central problem is to formulate multidimensional questions. These haveto be analyzed and answered in a dialogical process. Leading such a questioning process presupposes new skills. Let us emphasize that traditional scientific education is not good enough forthis. Of course, one must have sufficient knowledge about the subject matter, but most important is the skill to structure problem situations, in other words, the skill to specify different factors and to determine different functional balances of these factors. In fact, such a discussion has been under study in the philosophy of jurisprudence (Heiskanen, 1992). To get a better grasp let us consider the interrogative model of inquiry more closely.

\section{Interrogative Model of Inquiry}

\section{Questions}

Questioning can be seen as a general process of knowledge-seeking. That is, different types of knowledge-seeking processes can be analyzed as questioning processes. To do this systemically, we have to consider the logical structure of question-answer sequences more closely (Hintikka, 1984).

Questions can in a natural way be understood as requests for further information (Hintikka, 1976; Åqvist, 1965). That is, a questioner lacks some information, and he or she addresses the question to some source of information he or she thinks is a good source to get the information he or she needs. A given answer will - in a happy case - give the information needed. For example, the question

(1) Who lives here?

requests information about the person who lives here.

The situation in which the question (1) is rational to ask is that someone lives here. Such a condition is the presupposition of the question. So, the truth of the presupposition makes asking the question rational, since it guarantees that there is a correct answer to the question.

A question determines the class of potential answers to the question. That is, the (logical) nature of the question determines the kinds of answer that may be given to the question. For example, to the question (1) the class of potential answers is the class of people. A member of the class of potential answers is an answer (reply) to the question.

A conclusive answer to the question gives the information the questioner is searching for. However, not every answer (reply) is a conclusive answer. Conclusiveness presupposes that an answer is true. However, truth alone does not guarantee the conclusiveness. To understand conclusiveness we have to consider the formal logical properties of questions but also several practical and contextual factors. For example, in the analysis of the question-answer relationship the knowledge of the questioner has to be taken into consideration (Hintikka, 1976).

Each sentence divides all the possibilities into two separate classes: the class of possible states of affair in which the sentence is true, and the class of possible states of affair in which the sentence is false. Information is defined by the ability to exclude some of the possibilities (Hintikka, 1973). In this spirit, the knowledge one has separates the possible states of affair into two groups - the possible states of affair that are compatible to everything one knows, these are called his or her knowledge worlds, and the possible states of affair that are not compatible to everything one knows (Hintikka, 1991). 
An answer to a question has to convey the information the questioner needs. That is, an answer should allow the questioner to exclude so many of the possibilities that the questioner can uniquely identify the answer. However, by definition this depends on the knowledge the questioner has before asking the question.

Let us consider the following simple example. The questioner asks the question (1), and the answer given to him or her is ' $b$ ' where $b$ is a name. The answer does the job only if the questioner can identify the person to whom the name ' $b$ ' refers, that is, if the name ' $b$ ' refers in every questioner's knowledge world to one and the same person. That is, the answer does the job, if the questioner can truly say that 'I know who b is' (Hintikka, 1976).

Here we must note that the answer has two different functions. First, it has a function of a direct answer. The name ' $b$ ' is a direct - and true, as the questioner hopes - answer to the question (1). However, to bring about the conclusiveness it must at the same time give enough supplementary information to the questioner. That is, after the answer the questioner must have enough information in order to identify the person to whom the answer refers (Hintikka, Halonen, \& Mutanen, 2002).

To be able to question rationally the questioner must prove the presupposition of the question before he or she can ask it. This determines the constraints the questioner must know before asking the question. Moreover, the conclusiveness condition gives the information that must be conveyed by the answer. This determines the whole framework (in this simplified case) in the question-answer process. A closer analysis shows that the general structure of such a process is dialogical (Mutanen, 2002).

Such information-seeking questions have a clear-cut role in both scientific research processes and innovation processes. However, to get a better understanding let us characterize the role of questioning more precisely.

\section{Interrogative Model of Inquiry}

In science questions have different kinds of roles. Questions may denotethe main object (or main interest) in the inquiry. In this sense, for example, Laudan (1977) uses the notion of problem. Problems can be expressed via questions. Let us call questions that express the main problem of the inquiry main questions. The main question specifies the knowledge the whole research process is looking to find. However, there is also another meaning for questions in science. For example, Kant (1998) and Bacon (2000) used the notion of question in the scientific process in a more specified sense. The notion of question in this specified sense denotes the step of inquiry in which the inquirer requests further information in order to answer to the main question of the inquiry. In this latter meaning, questions have a central methodological role in an inquiry process. These minor questions map a route from ignorance to knowledge, that is, questions are seen as a methodological tool to convey the inquiry process to the intended goal (Hintikka et al., 2002, Kelly, 1996).

Scientific inquiry - knowledge-seeking, argumentation, and reasoning - can be seen as a series of questions and answers. This observation may sound quite obvious. However, systemat ic explication of the idea is an extremely difficult task. The int errogative model is one in which the idea is taken seriously. Scientific inquiry is a methodical search for knowledge; hence the questionanswer processes have to be characterized as strat egic processes - goal-tracking processes. The interrogative model is a general idea that can be applied in several different kinds of science; for example, Sintonen (1990) analyzes Darwin's work using an interrogative model.

The interrogative model has been a general approach to reasoning in the history of philosophy and science. The most famous example is the Socratic questioning method (elenchus). The very idea is that a questioning process is a strategic process leading the argument to the intended goal. The goal is often to show that the opinion (of an opponent) at the beginning is wrong. To acquire 
the goal Socrates asks questions that are yes-no questions, that is, questions whose potential answers are 'yes' or 'no'.

Aristotle further developed the interrogative model, especially in Topica. In Topica Aristotle developed a general strat egy to interrogative processes (interrogation games). Moreover, he separated two classes of answers that occur in the questioning processes: answers that are necessitated by the earlier answers, and all the other answers. His study of the answers of the first class started the study of logic. However, systematically speaking, logic is not a separate field of study, but a central part of the interrogative model (see Hintikka \& Bachman, 1991; Hintikka et al., 2002).

To take a more systematic approach, let us consider a line of reasoning: $\mathrm{P}_{1}, \ldots, \mathrm{P}_{\mathrm{n}}, \mathrm{C}$, where $\mathrm{P}_{\mathrm{i}}$ $(\mathrm{i}=1, \ldots, \mathrm{n})$ and $\mathrm{C}$ are propositions. If the argument is logically valid then we say that the conclusion $\mathrm{C}$ can be deduced from the premises $\mathrm{P}_{1}, \ldots, \mathrm{P}_{\mathrm{n}}$. In logic the interest is only in the logical formal - relationship between the propositions (sentences). This is also the case in the traditional analytic philosophy of science. That is, all the pragmatic aspects of scientific reasoning are excluded from the philosophical analysis (Sintonen, 1993). The interrogative model takes these logical aspects of reasoning into consideration, of course, but it also takes pragmatic aspects of reasoning explicitly into the model.

A nat ural, real life reasoning process is not a formal logical deduction that starts with the complete information. It is a knowledge-searching process in time and space. Some further information from some outer sources of information enters the process. The interrogative model characterizes the whole process of reasoning. To do this the nature and reliability of the sources are of central importance (Hintikka, 1991).

The interrogative model focuses on the rational search for knowledge. Here, rationality refers to rational evaluation of (sources of) information used in argumentation and to rationality of argumentation (methodology). So, rationality means a strategic approach: The questioning process has to be goal tracking. To do the task well questions and deductions must be syncretized (Hendricks, 2001; Hintikka \& Bachman, 1991).

Following Aristotle we will divide the premises into two classes: premises that can be deduced from the earlier ones, and others. The first call corresponds to logical inferences by the arguer, and the other class corresponds to questions asked by the arguer of an outer source of information. In a sense, the logical inferences explicate the information already exist ing in the argument, and questions bring new information into the argument (abduction). This new information makes interrogative inferences ampliative (Hintikka 2007).

The nature of the outer source of information has to be specified. To be rational knowledgeseeking the nature of the source must be known. Socrates was looking at the opinions of the people he was discussing. These people are at the same time sources of information. Socrates was interested in the opinion of the people. Hence, they were reliable sources of information. So, the method Socrates used was reliable. In natural science the source of information is nat ure. To get the information a scientist cannot ask questions directly but he or she must make observations and experiments. These are systematic and hence the reliability of the information can be evaluated (Hintikka, 1985; Hintikka et. al., 2002).

The essential thing is not that the source should be reliable. It is possible to argue rationally using unreliable sources of information (Hintikka, 1987; Hintikka et. al., 2002). For example, legal argumentation in a court of law does not assume that the information coming from the sources of information is reliable. In fact, the argumentation in the court evaluates the forthcoming information systematically (Hintikka, 1985; Holmström-Hintikka, 1995). The essentialthing is not reliability or not but to know the very nature of the forthcoming information (Osherson, Stob, \& Weinstein, 1986).

The very idea is that arguer has to be an active agent in knowledge-seeking. He or she is actively looking for the information needed in the process. All the new information comes via questions 
asked by the arguer. Methodologically, essential problems are what to ask, when to ask, and where to ask (what or who are good sources of this information). The first problem characterizes the structure of the main problem of inquiry, the second problem characterizes the strategic aspect of reasoning, and the third problem characterizes the context of the main problem of inquiry (Hintikka et al., 2002).

The nature of information sources varies from case to case. In the natural sciences the source of information is usually seen as a passive answerer. However, there is a big difference between pure observations and experiments (Hintikka, 1984). However, a source of information can be an active knowledge generat or (Kelly, 1996). As the example of Socrates shows, it is possible to develop the model in a direction in which the answerer also has an active role (see Hintikka, 1982; Mutanen, 2002).

To formulate the interrogative model more precisely we have to specify the fact ors of the model. To specify the model we have to specify (i) an inquirer, (ii) a problem to be solved, and (iii) the information that can, in principle, be obtained during the process. To specify the inquirer we usually specify the theoretical background of the inquirer. In a simple case the inquirer has a main question to answer. In the simplest case, all the forthcoming information comes from one and the same source and is known to be true (Hintikka et al., 2002).

The inquirer has to have a systematic method to explicate the inquiry process. In fact, it is not essential how this is tallied, but it must be systematic; it must allow the inquirer to explicate and document the reasoning process. The inquirer may make deductions and ask questions of an out er source of information. The results of the operations have to be specified in the documentation (Hintikka 1991).

The interrogative model is closely related to the traditional logical approach to the philosophy of science. However, the interrogative model brings something essential and new to the picture. Interrogative moves open the door to the outer world. Already this has a fundamental meaning. This can be seen if we ask what the ideal theory is according to the models. If we consider the simplest case, the traditional deductive view prefers a complete theory, and the interrogative model prefers a model complete theory. However, we know that these two are not interreduceable (Hintikka et al., 2002).

However, for us the most important aspect is that in the interrogative model epistemic aspects of inquiry processes are taken into the methodology. This makes the model very flexible. It can be applied to several different kinds of question-answer processes (See Hintikka \& Hintikka, 1982).

\section{Deliberative Arguments}

As we have emphasized, innovation is a goal-searching activity. However, the principal goal is not truth, but for example a new product or service. So, the search for truth does not play as central a role as in (basic) research. Hence, the above characterized presuppositions of knowledgeseeking questions do not play a central role. More central are the possibility and accessibility questions. The possibility refers to both the technological and the practical possibility. The first of these can be answered within scientific research; the latter refers to the local situation - to the possibilities within this company/society. Accessibility refers to the general values of society. In a sense, these can be understood as presuppositions of innovation questions. The truth of these presuppositions can be evaluated only through dialogue (Mutanen 2007).

In innovation the first and foremost problem is to deliberate the final goal. Of course, sometimes intuition as a fast mode of mental process may serve as a starting step. However, intuition is not good enough. We have to give a rational characterization of the innovation process. The qualifier 'rational' refers to a methodic process in a context. It is not enough to characterize a goal; one has also to specify the means of acquiring the goal: the means and the goal have to be synchronized. This is done in a deliberative argument. A deliberative argument is one in which the arguer is set- 
ting a goal for him- or herself, and tries to explicate the method that allows him or her to reach the goal.

It is possible to analyse deliberative arguments within an interrogative model. In a deliberative argument the initial premise (background knowledge) that the arguer has is not a theory, but rather the goal he or she is trying to attain. As a final conclusion the arguer gets to know what to do in order to reach the goal (Hintikka \& Bachman, 1991).

The interrogative process makes the route to the goal explicit. The mean (method) that leads to the goal is a final (ultimate) conclusion. In several cases there is no single act that gives the goal, but, rather, the argument it self maps a route to the goal. Moreover, deliberative arguments are often so closely connected to the practical behavior that (theoretical) argumentation and its application (action) cannot be separated (Hintikka \& Bachman, 1991, von Wright, 1963).

In such deliberative argumentation the sources of information (oracles) have to be specified. In a basic interrogative model - described above - the sources of information were characterized via observations or experiments. The theoretical background is given by the researcher. In the case of deliberative argumentation there is no such a background theory. The goal plays the role of the theory, and the goal may change during the process (Hintikka \& Bachman, 1991).

Now, sources of information may or rather should contain theoretical information (theory or theories). The theoretical information comes into the argumentation via a scientist - by a dialogical process. However, the search for such theoretical information leading a corresponding dialogue within a given context presupposes a special skill. No traditional field of science focuses on this problem. However, one needs a good basic knowledge about the relevant fields of science and practical skills - one has to understand the basic ideas of the substance and to be familiar with the context. There is a need for a new kind of expertise (Volanen, 2007).

Deliberative argumentation takes place in practical contexts. The argumentation is closely connected to practical decision-making. These practical decisions are not purely epistemic problems (what is the case). They are also connected to values (what should or could be our intent). Decisions have to be carried out. This has to be done well, which has an aesthetic aspect (how to do it well).

In principle these three different aspects can be separated. Sometimes this is done via a division of labour: epistemic aspects are the job of a scientist; the aesthet ic aspect is done by a designer; and the ethical aspect - well-doing - is done by a worker. However, in practical activity such separation is not possible. Practical activity and decision-making brings these aspects to the same place at the same time. They are practically inseparable (Hintikka, 1985; Mutanen, 2007).

The conclusion of the deliberative argumentation is a specification of the goal and a means that leads to the goal. The three dimensionality of the argumentation occurs in every level of the argumentation and, of course, in the implementation of the argument. Hence, the goal and the mean should be based on true, acceptable, and excellent knowledge. That is, truth is justified within the usual scientific process. However, these results have to be specific to the cont ext. Goal and means should be acceptable. However, this acceptance is always a collective act: the process of acceptance should be dialogical. Moreover, the goal should be attained well. To determine this welldoing is a collective, dialogical act (von Wright 1963).

Deliberative argumentation runs as a stepwise process within a practical context. The process starts with the arguer discovering and formulating brief statements of main ideas and materials for the goal. This has to be connected to the context explicitly. After this the arguer proceeds by analyzing the ideas and materials formulated already. This presupposes argumentation skills, but also several practical skills. After this one can see clearly what the ult imate goal is. Otherwise the process continues interrogatively by explicating information that already has been given or asking for further information (Mutanen 2007). 
The whole process has to be cooperative. In fact, this cooperativeness is a clear-cut consequence of the analysis above. Moreover, a closer look at the argument above shows that dialogicality (or cooperativeness in a strong sense) is a methodological recommendation in an innovation process. That is, cooperativeness is not an external rule but is built into the methodology of innovation.

(See Figure 1.)

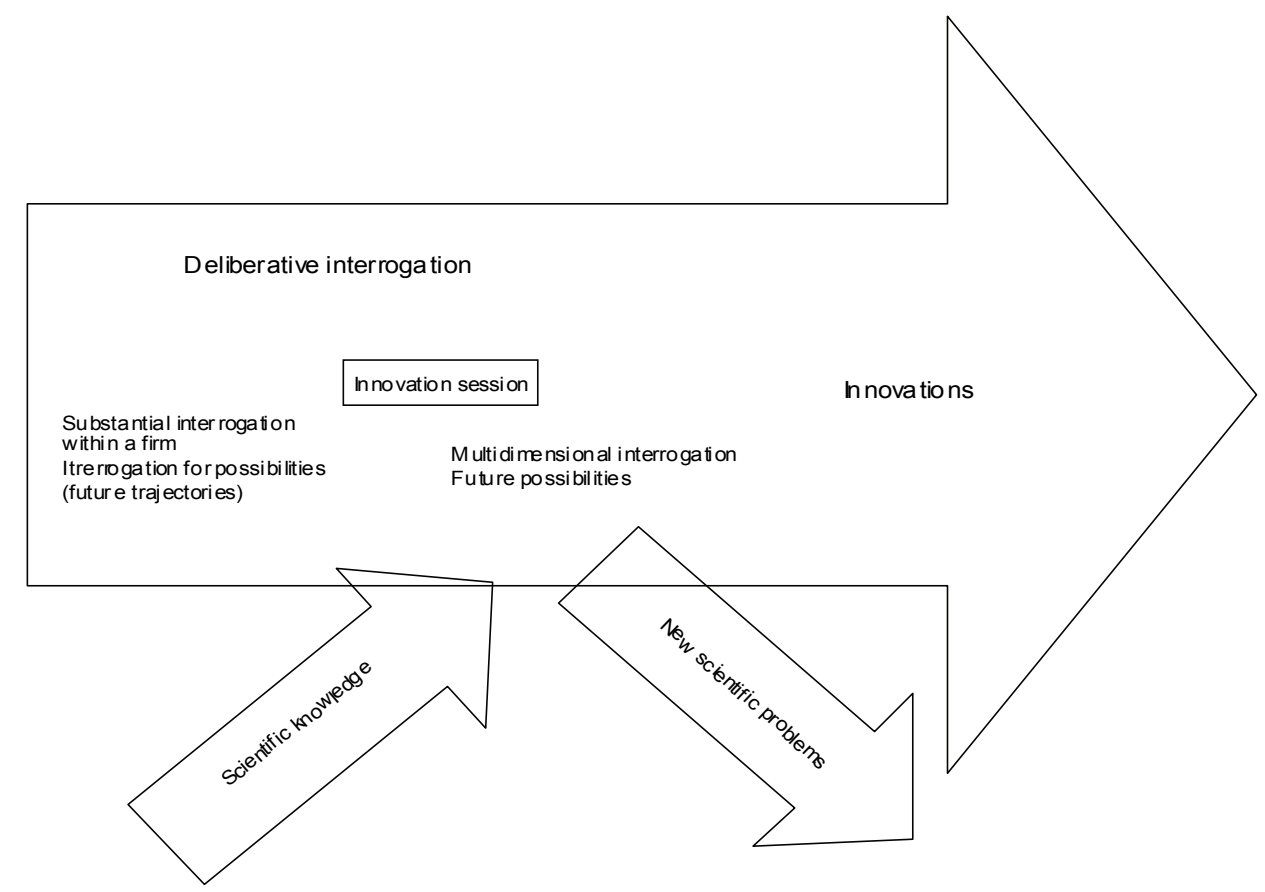

Figu re 1: Principles of interrogative model

\section{Mental Exercise: Mode 2 Knowledge Production in a Structural Hole (Metal Industry - Nanotechnology)}

The Lahti region has set a goalto be the leading area in practice-based innovation activities in Finland (see Aula \& Harmaakorpi, in press). In the region the framework of network-facilitating innovation policy has been developed in order to promote practice-based innovation activities (see Harmaakorpi \& Tura, 2006). The Lahti region's fut ure competitiveness is seen to be greatly dependent on its ability to promote practice-based innovations, due to the absence of a university and very low research inputs in the region. Although lacking its own scientific research the Lahti region has a favorable logistic situation; it lies only $100 \mathrm{~km}$ from two remarkable research centers, Helsinki and T ampere, enabling the relatively easy transfer of scientific knowledge to the practice-based innovation processes. The yearly research inputs in 2004 per person were 1800 euros in the Helsinki region and 2530 euros in the Tampere region whereas in the Lahti region it was only 255 euros per person.

The situation in the Lahti region has forced it to develop new tools to trigger innovation processes. One aim of the network-facilitat ing innovation policy is to search for structural holes between the regional knowledge-base and the scientific knowledge-base found in the surrounding research centers. The normal procedure of gett ing new innovation processes triggered is as follows. The innovation experts in the intermediate organizations approach local firms and analyze the possible fut ure trajectories and the knowledge needed to reach those trajectories. This analysis often reveals some structural holes to be spanned. After careful preparation work a one-day innovation session is held. The innovation session method is an integrated process in which planning, 
Harmaakorpi \& Mutanen

acting, and implementing must all be synchronized. The synchronizing process is a contextsensitive dialogical process.

The aim in the Lahti region is to organize 30 practice-based innovation sessions per year in the region. The participants include experts from companies, top-level experts often from the world of science, and members of the intermediate organizations. An innovation session begins with introductory speeches given by the experts chosen to fit the theme of the day. After the introductory speeches the creativity operat or promotes interaction between the participants in order to discover the innovation potential lurking in the structural holes. The aim is to find $2-4$ potential ideas to pave the way for new networked multi-actor innovation processes utilizing Mode 2 knowledge production (Harmaakorpi, 2006).

How difficult it is to reach a fruitful dialogue between the participants of the innovation session has often been seen since the knowledge interests are too far from each other, threatening the spanning of the structural hole. In such situations, using the methodology of the interrogative model of inquiry has been very helpful. Below we make a mental exercise where we use the interrogative model in filling the structural hole existing between the basic research of nanotechnology and practical development work in the metal industry. The innovation potential is clear but the innovation processes are inadequate due to the lack of communication. We conceptualise three archetypes of participants in an innovation session i) nanotechnology knowledge producers, ii) metal industry knowledge exploiters, and iii) inter-mediators. The following mental exercise is not based on any individual case. It is rather a synthesis of the experiences gained in many innovation sessions. Therefore, it is imaginary but strongly based on real events (Harmaakorpi \& Tura, 2006; Reason \& Bradbury, 2006; Mutanen, 2007).

After the introductory speeches, the mental distance of the participants is often quite long. Scientists are still thinking in theoretical questions like "How could I get still longer nanocoal tubes?", company representatives could still be thinking about "How could I make my product stronger?" and the inter-mediators think "How could I get the people to begin to solve a common problem?". In a sense, both in science and at company level, the questioning-answering process is onedimensional. By his or her questioning, the intermediat or makes the questioning-answering process multidimensional, i.e., crosses boundaries between these two contexts. Practical problems in the context can be understood as a tool in this boundary crossing (Engeström, 2005; Mutanen, 2007).

The basic problems for the innovation process come from the metal industry. There is a need for further development. This is a permanent state in modern business. However, the usual steps of development are not enough. There is a need for something really new - genuine innovation. However, nobody knows what this genuine innovation could be - this is the case by definition. There is something that can be done. The metal industry company has to be locat ed within a new context in which problems can be formulated and answered in a new way (Harmaakorpi \& Tura, 2006).

To specify the new cont ext one has to analyze the situation of the company. This analysis consists of the factual analysis of manufacturing and cultural factors. This allows one to specify weak ties that may be fruitful. However, to specify potential fruitful weak ties is not enough. One central property of weak ties is that they are only potential. To actualize the potentiality of the ties one has to activate the tie. To do this one has to motivate all the partners to take a new perspective (Engeström, 2005).

In the company the analysis of the situation pictured above makes this step possible. A scientist is not principally interested in problems within a context in a company. He or she is looking for general new knowledge. Moreover, in a company it is not enough that exist ing knowledge be applied in solving some problems. The whole framework has to be specified in a new way. This cannot be done without the help of the scientist. That is, the scientist has to do proper research within the context. This is a new challenge for the scientist. After this the context will be opento 
a dialogical process. The time and space for the dialogue has to be organized. This has to be an open-minded situation in which all the co-operators are present in full force (Mutanen 2007).

The basic idea is the following. In scientific research of nanotechnology the basic problems are connected to the basic theory and its development. In the metal industry the basic problems are connected to basic processes in making products and developing exist ing processes and products. Even if in nanotechnology the intention is to apply the theoretical knowledge in practical problems, there would be a gap between the two; in the metal industry the existing machinery and habits in production may cause some difficulty in applying scientific knowledge.

In an innovation session the very idea is to bring together these two: nanotechnology researchers and practical metal industry actors. The first problem is to get a common understanding about the practical context in which innovation should occur. After this the process is directed to fertilize the dialogue between the partners. This is just eliciting multidimensional questions that allow dialogue to proceed. In fact, this means that nanotechnology experts will ask context dependent questions, that is, questions that arise from the practical context. This is neither basic research nor just applying existing knowledge. It is about understanding the underlying practical context as a practical context. This understanding allows the multidimensional questions to be answered. The metal industry participants have to act in a similar manner.

Reaching a common understanding of the problem by the efforts of knowledge producers and knowledge exploiters has proven to be problematic in many cases. In a short time schedule the role of information brokers has proven to be essential in making the participants innovate. The task of the inter-mediat ors is very challenging, since they need to understand the processed substance knowledge, as well as have the social abilities to work in very diverse groups. To secure a successful innovation session inter-mediat ors need to be able to set questions and deliberative arguments that, for example, enable i) the people on both sides of the structural hole to become aware of the interests and difficulties of the other group, ii) transferring the best practices between the groups, iii) drawing analogies between groups ostensibly irrelevant to one another, and iv) making a synthesis of the knowledge interests (Burt, 2004).

\section{Concluding Remarks}

Focusing on a network-facilitat ing innovation policy in promoting practice-based innovation activities, in particular, has created new demands for innovation operations in the Lahti Region in Finland. The coordinated search for innovations in the structural holes has revealed a lack of appropriate methodological approaches to activate the innovation potential in these holes.

The experiences gained in 30 innovation sessions show that, for example, the familiar brainstorming methods do not work very well with this kind of innovation session. The knowledge interests of the innovating partners often remain too distant to enable an active multi-actor innovation network to emerge. After many trials it became clear that the right questions set in the group work in the innovation sessions could open up the way for successful innovation processes. This trajectory led us to find the interrogative model of inquiry as a possible methodological approach to use in the networked innovation processes aiming at spanning the structural holes. The model being developed in the field of theoretical philosophy poses a fascinating intellectual challenge to apply the model in the context of innovation systems.

The Lahti Region is moving towards using the interrogative model of inquiry in its innovation promotion activities. Although application of the model is still in its embryonic phase, it has proven to have potential for further development. The first experiences emphasize the role of intermediate organizations - information brokers - in a successful questioning process. The actors in these organizations seem to lack the qualifications needed to process questions and deliberative arguments in the inquiry process. Therefore, the next steps in making the interrogative model of inquiry really work in the innovation processes in the region is i) to develop the model to better suit the practical work by trying different kinds of inquiry scenarios in the innovation sessions, 
and ii) to educate the actors in the intermediate organizations to use the interrogative model of inquiry in the information brokerage in the innovation sessions.

The managerial impacts of using a tool like the interrogative model are remarkable. The issue actually concerns creativity management in structural holes. The key notions in this management process are tolerance, uncertainty, interrogation, and interpretation. The interrogative model is a tool for managing interpretable innovation processes - ratherthan problem-solving innovation processes (see Lester \& Piore, 2004). Therefore, management that ut ilises the interrogative model is quite likely to be based on actions of leadership, not management (cf. Bennis, 1989). A detailed assessment of managerial implications is beyond the scope ofthis study. However, Amabile (1997) paves the way for essential questions in managing interpretable innovation processes by dividing creativity into three different components: expertise, creative-thinking skills, and motivation. Promoting expertise with the interrogative model refers to managerial abilities to make possible worlds visible for the innovating partners; promoting creative-thinking skills refers to managerial abilities to span the structural holes; and promoting motivat ion refers to managerial abilities to motivate people with very different backgrounds to focus on the same innovation process.

\section{References}

Amabile, T. M. (1997) Motivating creativity in organizations: On doing what you love and loving what you do. California Management Review, 40(1), 39-58.

Aula, P., \& Harmaakorpi, V. (in press). An innovative milieu: a view on region reputation building. Regional Studies.

Autio, E. (1998). Evaluation of RTD in regional systems of innovation. European Planning Studies, 6(2), 131-140.

Bacon, F. (2000). The new organon. (L. Jardine \& M. Silverthorne, Eds.), Cambridge : Cambridge University Press.

Bennis, W. (1989). On becoming a leader. Reading, MA, USA: Addison-Wesley.

Burt, R. S. (1992). Structural holes: The social structure of competition. Boston: Harvard University Press.

Burt, R. S. (1997). The contingent value of social capital. Administrative Science Quarterly, 42, 339-365.

Burt, R. S. (2004). Structural holes and good ideas. American Journal of Sociology, 110(2), 349-399.

Edquist, C. (1997). Systems of innovation approaches - Their emergence and ch aracteristics. In C. Edquist (Ed.), Systems of innovation: technologies, institutions and organizations (Chapter 1). London, UK/ Washington, D.C., USA: Pinter Publishers.

Engeström, Y. (1999). Activity theory and individual and social transform ation. In Y. Engeström, R. Miettinen, \& R.-L. Punamäki (Eds.), Perspectives on activity theory. Cambridge University Press.

Engeström, Y. (2005). Developmental work research: Expanding activity theory in practice. Berlin: Lehmanns Media.

Gibbons, M., Limoges, C., Nowotny, H., Schwarzman, S., Scott, P., \& Trow, M. (1994). The new production of knowledge. London: Sage.

Granovetter, M. (1973). The strength of weak ties. American Journal of Sociology, 78, 1360-1380.

Granovetter, M. (2005). The impact of social structure on economic outcomes. Journal of Economic Perspectives, 19(1), 33-50.

Harmaakorpi, V. (2006). The regional development platform method as a tool for regional innovation policy. European Planning Studies, 14 (8), 1085-1104.

Harmaakorpi, V., \& Tura, T. (2006). Practice-bas ed innovation activities and network-facilitating innovation policy. International ProAct Conference: Innovation Pressure - Rethinking Competitiveness, Policy and the Society in a Globalised Economy, 15th-17th March 2006, Tampere, Finland. 
Heiskanen, V. (1992). International legal topics. Helsinki: Finnish Lawyers' Publishing Co.

Hendricks, V. F. (2001). The convergence of scientific knowledge - A view from the limit. Dordrecht: Kluwer Academic Publishers.

Hendricks, V. F., \& Pedersen, S. A. (1997). A note on innovation and justification. Danish Yearbook of Philosophy, 32, 87-110.

Hintikka, J. (1973). Logic, language games and information. Clarendon Press.

Hintikka, J. (1976). The semantics of questions and the questions of semantics. Acta Philosophica Fennica 28(4). Helsinki: Societas Philosophica Fennica.

Hintikka, J. (1982). A dialogical model of teaching. Synthese, 47, 39-59.

Hintikka, J. (1984). Questioning as a philosophical method. In H. Fetzer (Ed.), Principles of philosophical reasoning. Rowman.

Hintikka, J. (1985). Legal reasoning and legal system. In Bulygin et al. (Eds.), Man, law and modern forms of life (pp. 209-220). D. Reidel.

Hintikka, J. (1987). The interrogative approach to inquiry and probabilistic inference. Erkenntnis, 26, 429442.

Hintikka, J. (1991). Towards a general theory of identi fiability. In J. Fetzer, D. Shatz, \& G. Schlesinger, (Eds.), Definitions and Definability (pp. 161-183). Dordrecht: Kluwer Academic Publishers.

Hintikka, J. (2007). Abduction - Inference, Conjucture, or an Answer to a Question. In J. Hintikka, Socratic epistemology. Cambridge University Press.

Hintikka, J., \& Bachman, J. (1991). What if ...? Mayfield Publishing.

Hintikka J., Halonen, I, \& Mutanen, A. (2002). Interrogative logic as a general theory of reasoning. In R. H. Johnson \& J. Woods (Eds.), Handbook of practical reasoning. Dordrecht: Kluwer Academic Publishers.

Hintikka, J., \& Hintikka, M. B., (1982). Sherlock Holmes confronts modern logic: Toward a theory of information-seeking through questioning. In E. M. Barth \& J. L. Martens (Eds.), Argumentation: Approaches to theory formation (pp. 55-76). Benjamins.

Holmström-Hintikka, G. (1995). Evidence, experts and legal reasoning. Communication \& Cognition, 28(1), 7-36.

Howells, J. (2000). Knowledge, innovation and location. In J. R. Bryson, P. W. Daniels, N. Henry, \& J. Pollard (Eds.), Knowledge, space, economy. London/New York: Routledge.

Innovation in Europe. Results for the EU, Iceland and Norway. (2004). Community innovation survey, data 1998-2001. Luxembourg: Office for Official Publications of the European Communities.

Kant, I. (1998). Critique of pure reason. (P. Guyer \& A. W. Wood. Trans. \& Eds.). Cambridge, New York: Cambridge University Press

Kelly, K. (1996). The logic of reliable inquiry. London: Oxford University Press.

Kline, S., \& Rosenberg, N. (1986). An overview on innovation. In R. Landau, \& N. Rosenberg, The positive sum strategy (pp. 275-305). Washington, D.C.: National Academy Press.

Laudan, L. (1977). Progress and its problems: Toward a theory of scientific growth. Berkeley University of Californi a Press.

Lester, R., \& Piore, M. (2004). Innovation - The missing dimension. Cambridge: The Harvard University Press.

Lundvall, B.-Å. (1988). Innovation as an interactive process: From user-producer interaction to the national system of innovation. In G. Dosi, G. Freeman, R. Nelson, G. Silverberg, \& L. Soete (Eds.), Technical change and economic theory (pp. 349-369). London/New York: Pinter Publishers.

Lundvall, B.-Å., \& Borrás, S. (1999). The globalising learning economy: Implications for innovation policy. Luxembourg: Office for Official Publications of the European Communities. 
Mutanen, A. (2002). Interrogative model of learning. In M. Kiikeri \& P. Ylikoski (Eds.), Explanatory connections electronic essays dedicated to Matti. Retrieved June 2008 from http://www.valt.helsinki.fi/kfil/matti/mutanen.pdf

Mutanen, A. (2007). Methodology of engineering science as a combination of epistemic, ethical and aesthetic aspects. In S. Hyldgaard (Ed.), Philosophy in Engineering (pp. 123-138). Aarhus, Denmark: Acad emica.

Technology, productivity and job creation. Best policy practices. (1998). OECD: Paris, France.

Osherson, D., Weinstein, S., \& Stob, M. (1986). Systems that learn. MIT Press.

Reason, P., \& Bradbury, H. (Eds.). (2006). Handbook of action research. London: Sage.

Schienstock, G., \& Hämäläinen, T. (2001). Transformation of the Finnish innovation system. A network approach. Sitra Reports series 7. Helsinki, Finland: Hakapaino Oy.

Schumpeter, J. A. (1942). The theory of economic development. London: Oxford University Press.

Sintonen, M. (1990). How to put questions to nature. In D. Knowles (Ed.) Explanation and its limits (pp. 267-284). Royal Institute of Philosophy Supplement 127. Cambridge: Cambridge University Press.

Sintonen, M. (1993). In search of explanations: From why-questions to Shakespearean questions. Philosophica, 55-81.

Volanen, M. V. (2007). Craft and art in engineering. In S. Hyldgaard (Ed.), Philosophy in engineering (pp. 123-138). Aarhus, Denmark: Acad emica.

von Wright, G. H. (1963). Norm and action. Routledge and Kegan Paul.

Walker, G., Kogut, B., \& Shan, W. (1997). Social capital, structural holes and formation of an industry network. Organization Science, 8(2), 109-125.

Zaheer, A., \& Bell, G. G. (2005). Benefiting from network position: Firm capabilities, structural holes, and perform ance. Strategic Management Journal, 26, 809-825.

Åqvist, L. (1965). A new approach to the logical theory of interrogetives. Uppsala: Filosofiska Föreningen.

\section{Biographies}

Dr. Ves a Harmaakorpi is professor of innovation systems at Lappeenranta University of Technology, Lahti Unit (Lahti, Finland). Professor Harmaakorpi has his background in business life. The last ten years he has worked within the university community. His research interests are innovation systems and processes as well as innovation environments linked to regional development.

Dr. Arto Mutanen is Senior Researcher at Lappeenranta University of Technology, Lahti Unit. He gained his doct orate in philosophy (theoretical philosophy) from University of Helsinki. Research topics have been related to philosophy of science, methodology, philosophical logic, and philosophy of expertise. 